MATEC Web of Conferences 22,04017 (2015)

DOI: $10.1051 /$ matecconf/ 20152204017

(C) Owned by the authors, published by EDP Sciences, 2015

\title{
Research of Effective Width of FRP U-shaped Hoop Reinforcement Properties of Concrete Beams by Shear
}

\author{
Baokun Li \\ Architectural Engineering, Chang'an University, Xi'an, Shaanxi, China
}

\begin{abstract}
The paste fiber reinforced composite material (hereinafter referred to as FRP) U-shaped hoop of reinforced concrete beams interfacial debonding is an important reinforcement technology research. For the effective width of the CFRP U-shaped hoop reinforcement, it is still a lack of in-depth research, only relying on the test research huge workload, this article (ANSYS) and the numerical simulation in the whole process of the shear load release properties of finite element calculation software. According to the results of finite element analysis, the author studied the CFRP U-shaped hoop to increase the width of the shear capacity of reinforced concrete beams by the impact.
\end{abstract}

Keywords: fiber-reinforced composite material; effective width; shear stripping; finite element analysis

\section{INTRODUCTION}

In many ways of reinforcing concrete structure, due to the high fiber fabric strength, light weight, easy construction, durability, it cannot change the size of the original structure, and receive more attention. For the current study focused on the most CFRP for CFRP flexural reinforcement, the shear reinforcement is for the study in small areas. Force model and the failure mechanism of concrete beams are under shear failure due to more complex than flexural destruction, the current concrete beam and paste CFRP shear strengthening is not entirely clear. Where the width of the fabric for different $U$-shaped hoop contributes to the shear capacity of reinforced concrete and there is no clear conclusion. This paper based on the finite element numerical simulation, is intended for different widths of cloth pasted U-shaped hoop shear strengthening of reinforced concrete beams to study more aspects.

\section{EXPERIMENTAL INTRODUCTION}

Dimensions beam experiments conducted herein is shown in Figure 1, using two approaches load, the longitudinal reinforcement and the stirrup beam configuration are the same. The longitudinal reinforcement bars are configured by Ultra in order to make the first reinforced concrete beam shear failure, rather than damage flexural. Both sides of the stirrups of steel reinforced concrete beam configuration for asymmetric configuration are in order to ensure the destruction occurred in reinforced concrete beam reinforced FRP side, the longitudinal reinforcement and the stirrup reinforcement beams are shown in Figure 2:

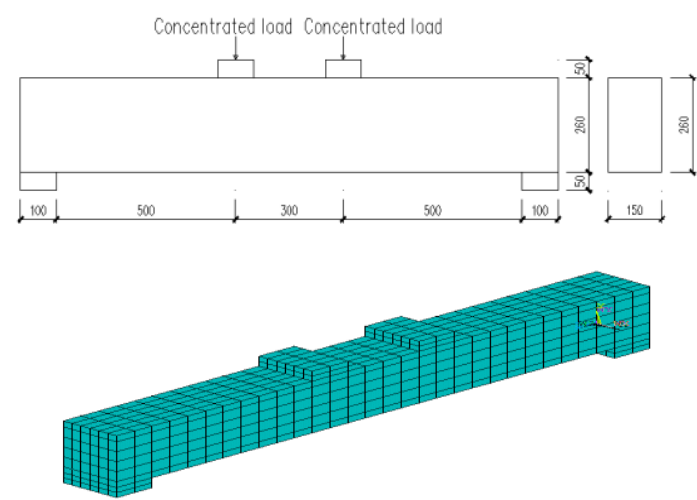

Figure 1. Finite element model dimensions

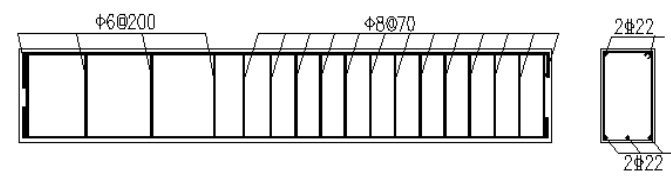

Figure 2. Steel arrangement

In this paper, six steel reinforced concrete beams used in comparative trials in which a beam is not controlled the CFRP reinforce reinforced concrete beams, the reinforced CFRP wrapped beams used in the form of a U-shaped parcel that both sides of the beam bottom, beams parcels, and surface exposed beams in the two free ends of the U-shaped fiber ferrule and there is no anchorage. The remaining five different carbon fiber reinforced beams were pasted in different widths 
MATEC Web of Conferences

Table 1. Test program.

\begin{tabular}{|c|c|c|c|c|c|c|c|c|}
\hline $\begin{array}{l}\text { Beam } \\
\text { number }\end{array}$ & $\begin{array}{l}\text { Reinforcement } \\
\text { materials }\end{array}$ & $\begin{array}{l}\text { Width } \\
(\mathrm{mm})\end{array}$ & $\begin{array}{l}\text { Spac- } \\
\text { ing }(\mathrm{mm} \\
)\end{array}$ & $\begin{array}{l}\text { Longitudinal } \\
\text { reinforcement } \\
\text { yield strength } \\
(\mathrm{MPa})\end{array}$ & $\begin{array}{l}\text { Stirrups } \\
\text { yield } \\
\text { strength } \\
(\mathrm{MPa})\end{array}$ & $\begin{array}{l}\text { Reinforcement } \\
\text { way }\end{array}$ & $\begin{array}{l}\text { With } \\
\text { fixed rate }\end{array}$ & $\begin{array}{l}\text { Fiber dis- } \\
\text { tribution } \\
\text { rate }\end{array}$ \\
\hline $\mathrm{S}-0$ & no & 0 & - & 310 & 263 & no & $0.19 \%$ & 0 \\
\hline S-1 & CFRP & 30 & 100 & 310 & 263 & $\mathrm{U}$ & $0.19 \%$ & $0.034 \%$ \\
\hline S-2 & CFRP & 50 & 100 & 310 & 263 & $\mathrm{U}$ & $0.19 \%$ & $0.049 \%$ \\
\hline S-3 & CFRP & 60 & 100 & 310 & 263 & $\mathrm{U}$ & $0.19 \%$ & $0.055 \%$ \\
\hline S-4 & CFRP & 80 & 100 & 310 & 263 & $\mathrm{U}$ & $0.19 \%$ & $0.066 \%$ \\
\hline S-5 & CFRP & 450 & - & 310 & 263 & Full length U & $0.19 \%$ & $0.148 \%$ \\
\hline
\end{tabular}

of CFRP reinforced concrete test beams, reinforced concrete beam test pasted cloth of width and other parameters in Table 1.

For pasting different widths CFRP of reinforced concrete beam, CFRP elastic modulus of $220 \mathrm{GPa}$, tensile strength of $3945 \mathrm{MPa}$, the thickness of one layer is $0.111 \mathrm{~mm}$, pasting different widths CFRP reinforced concrete U-shaped hoop schematic view of the beam is shown in Figure 3:

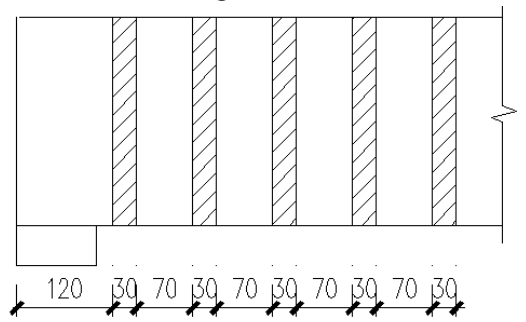

(a)fiber cloth width $30 \mathrm{~mm}$

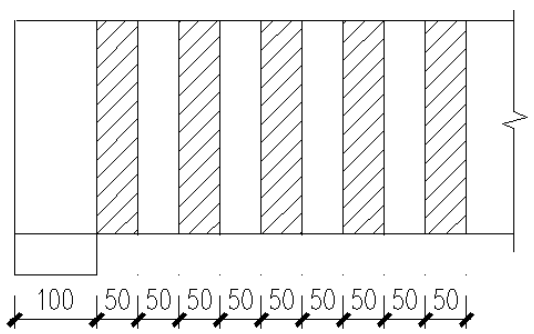

(b) ffiber cloth width $50 \mathrm{~mm}$
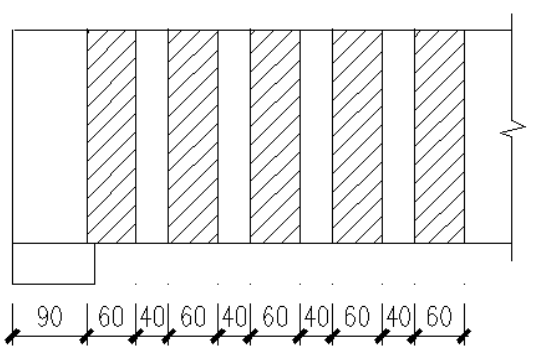

(c) fiber cloth width $60 \mathrm{~mm}$

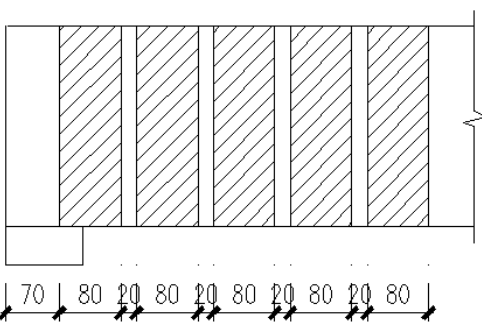

(d) fiber cloth width $80 \mathrm{~mm}$

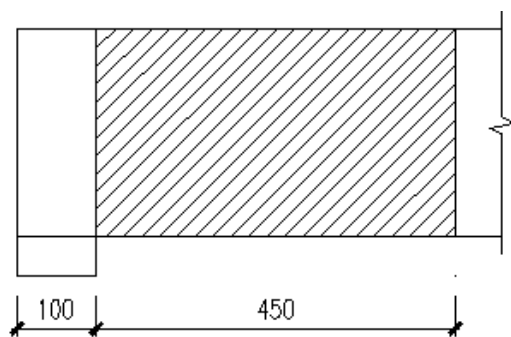

(e) fiber cloth width is $450 \mathrm{~mm}$

Figure 3. CFRP width layout

\section{FINITE ELEMENT MODEL DIMENSIONS}

Properly simulate concrete interface and bonding properties of CFRP interface is crucial for numerical analysis. In order to achieve the simulation effects, these paper models all use solid modeling, the concrete adopts reinforced concrete solid elements solid65; the pad adopts orthotropic anisotropy materials unit solid45; CFRP adopts putamina element shell41; rebar adopts separate modeling and model is set by line unit link8. Rebar and concrete of finite element model adopt separated models and the bonding that between steel and concrete are considered being reliable. Both units share same nodes.

This article takes the concrete as a continuous homogeneous material, and the concrete uniaxial com- 
ICETA 2015

pressive stress-strain curves uses Guo Zhenhai recommendations. This paper also takes the Von-Mises yield criterion as cracking criterion, which uses Rankine maximum tensile stress criterion, and uses diffusion-type fracture model. The ideal elastic-plastic material reinforced is taken into consideration, and FRP is based on elastic material consideration. Ultimately, the destructive testing of beams is controlled by stripping of FRP. After the stripping FRP calculation, it will no longer converge, and the calculation is finished. FRP and concrete interface unit adopt the following bond-slip relationship:

$$
\tau=\tau_{\max } \sqrt{\frac{\delta}{\delta_{\max }}}
$$

Among them, $\tau_{\max }$ is for bond strength; $\delta_{\text {max }}$ is for the maximum slip displacement corresponding to $\tau_{\text {max }}$.As a result of smeared crack model, the stress and strain of uniform are changed because the bond stress is the derivative with FRP strain, and the analysis of bond stress finite element will be less than the test beam resulting in local bond stress. In this paper, the calculation is used to reach the beam cross-section of bond stress test subject when the SHEAR carrying capacity as the bond strength is calculated, and the value is $1.867 \mathrm{MPa}$. In addition, this article assumes that the simplified FRP concrete cloth relative slip mainly occurs in the direction of the height of the beam which is in the direction of the displacement of the other two co-nodes and nodes on concrete fiber cloth.

The finite element calculation of concrete structures is very sensitive to certain model parameters, including cracks in shear transfer coefficient greatest impact. The SOLID65 crack concrete entity element integration point has two states: open and close, namely the crack open definition of shear transfer coefficient $\beta_{\mathrm{t}}$ and the closed fractures shear transfer coefficient $\beta_{c}{ }_{c}$. Based on numerical analysis, when the monotonic loading beam is in the whole process of the case load, the cracks are at the open state, only a few cells in a small number of cracks will appear to be closed. Therefore, the beam stiffness of open fracture shear transfer coefficient $\beta_{\mathrm{t}}$ plays a decisive role. At the same time, we cannot ignore the influence of crack closure shear transfer coefficient $\beta$ c to calculate the results, because if the two coefficients have much difference, it will make the individual position of the beam a severe stress concentration, and cause results not to converge. Similarly, if the two factors are too close, it is unreasonable too. The ability to transfer shear cracks which is closed is obviously a lot stronger than the crack opening, the beam will be constructed so that the stress concentration is no longer presented. It does not reflect the actual concrete beams by shear destruction, which may make the original beam shear failure should be considered to have been destroyed by the bend. Based on the calculation results after synthesis, take crack shear transfer coefficient: unre- inforced $\beta_{\mathrm{t}}=0.03, \quad \beta_{\mathrm{c}}=0.3$; reinforcement beams $\beta_{\mathrm{t}} \stackrel{\beta_{\mathrm{t}}}{=} 0.06, \beta_{\mathrm{c}}=0.6$.

\section{MAIN NUMERICAL RESULTS}

In the simulation, in addition to the comparative beam, the destruction of the rest of the test beam process is started the CFRP U-shaped hoop stripped from the side of the beam. Comparative tests include different widths of paste CFRP. Ultimate load tests of reinforced concrete beams and the middle deflection of beam are shown in Table 2:

\begin{tabular}{|c|c|c|}
\hline $\begin{array}{l}\text { Beam num- } \\
\text { ber }\end{array}$ & $\begin{array}{l}\text { Ultimate load } \\
(\mathrm{KN})\end{array}$ & $\begin{array}{l}\text { Span deflection } \\
\text { at failure }(\mathrm{mm})\end{array}$ \\
\hline S-0 & 159.3 & 2.14 \\
\hline S-1 & 216.0 & 3.17 \\
\hline $\mathrm{S}-2$ & 226.8 & 3.27 \\
\hline S-3 & 240.3 & 3.51 \\
\hline S-4 & 222.7 & 3.18 \\
\hline S-5 & 223.1 & 3.21 \\
\hline
\end{tabular}

\subsection{Girder span deflection}

The load-deflection curve of reinforced concrete beam loading process is shown in Figure 4. It can be seen from the figure that the span deflection of beam with no reinforcement CFRP is increased with the increasing load and the deflection amplitude is increased very significant. This is because the load is firstly increased to withstand the pressure which is concrete when the concrete that reaches the yield strength stirrup plays a role. And the right level of steel stirrups is a diameter of $6 \mathrm{~mm}$ with spacing which is $200 \mathrm{~mm}$ when the damage that occurred in the stirrups was cut with not reaching the yield strength. When the load is increased by $159.3 \mathrm{KN}$, the concrete shear fails.

The reinforced concrete beams span deflection CFRP strengthening in the early load is increased as the load increased significantly. This phenomenon shares the same performance characteristics with no reinforcement CFRP reinforced concrete beams, both are firstly by concrete and steel scissors to bear shear. In the late loaded reinforced concrete beams, it is slowly increased with the increasing load, then the CFRP plays a role in inhibiting the development of cracks so that the deflection is slowly increased. Finally, the load is increased to the limit load of CFRP stripped and the reinforced concrete beams shear failure.

The span deflection of reinforced concrete beams and ultimate carrying capacity do not correspond with the width of CFRP strip, however, when the CFRP strip width is $60 \mathrm{~mm}$, the ultimate load and span deflection of the beam reaches the maximum. When 


\section{MATEC Web of Conferences}

the width of the strip continues to increase to $450 \mathrm{~mm}$, the ultimate load and deflection of the beam span is decreased. It is because the pasted CFRP strips are too wide or the CFRP sheets and flexural deformation of the beam caused by inconsistent CFRP U-shaped hoop are released early, leaving the specimen damage.

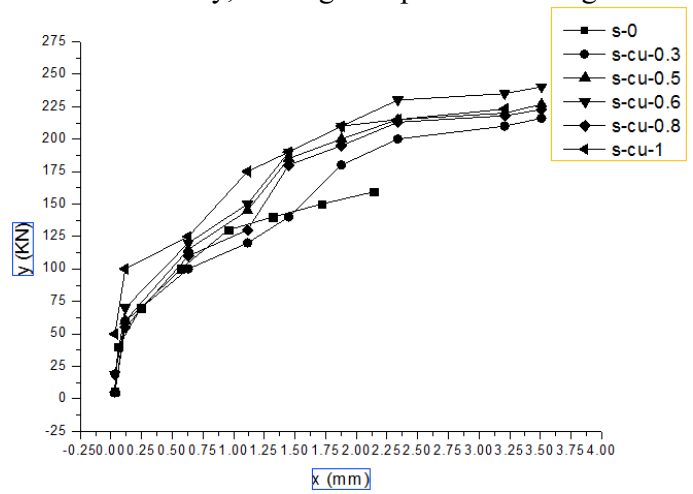

Figure 4. Load-deflection curve

In the $\mathrm{S}$ series, the average of the maximum deflection reinforced CFRP strips of concrete beam (width of $30 \mathrm{~mm}, 50 \mathrm{~mm}, 60 \mathrm{~mm}, 80 \mathrm{~mm}$ ) at failure is $3.28 \mathrm{~mm}$, while the reinforced concrete beams reinforced CFRP sheets (width $450 \mathrm{~mm}$ ) damage when the average of the maximum deflection is $3.21 \mathrm{~mm}$, which explained the pasted CFRP sheets rather than pasting CFRP strips that can delay the appearance of cracks and limit the development of cracks in the cracks, thereby increasing the stiffness of the beam.

\subsection{Strengthening the contribution of shear capacity of CFRP}

As Table 2 shows, compared with the compared reinforced concrete control, the shear capacity of reinforced concrete beams with CFRP is significantly increased, especially the reinforced concrete beams with the pasted CFRP U-shaped hoop strip which improves an average of $42 \%$ compared to the control (S-0), while the reinforced concrete beams with U-shaped pasted CFRP sheets that improve an average of $40 \%$ than the compared reinforced concrete beam (S-0). This result confirms the pasting CFRP strips and the CFRP sheets that they can improve the shear resistance of the beam effectively. The advantage of reinforced concrete beams with CFRP strip U-shaped hoop compared with reinforced concrete beams with CFRP sheets U-shaped hoop is that when reinforced concrete beams with CFRP strip U-shaped hoop, two adjacent strips can independently bear the main load across the CFRP fiber direction. When the CFRP strips are partial loss, they do not affect the performance of the adjacent CFRP strips, so that the shear capacity is decreased slowly. For the reinforced concrete beams with the CFRP sheets U-shaped hoop concrete beams, when the CFRP sheet is peeled, it will lead to the decrease of shear capacity of the beam. But the cracks continue with increasing load. During the development of the crack, CFRP sheets are gradually falling off until they are breaking. Therefore, the reinforced concrete beams with CFRP strip U-shaped hoop CFRP strain contribute more than the reinforced concrete beams with CFRP sheets U-shaped hoop and

\section{3 strain of carbon fiber sheet}

According to the experimental arrangement of the simulated load, it can be drawn that the bending and shearing zone are located between the support and the load position, the pure bending zone is located between two concentrated loads. Figure 5 is a strain contours of reinforced concrete beams strengthened with different carbon fiber widths of cloth U-shaped hoop, and the shear strain is increased along with the emphasis of color. From the fiber cloth width of strain contours which is $30 \mathrm{~mm}$, it can be seen that in the vicinity of the neutral axis, the shear strain is in creased. In the trace locations along the principal stress, the intermediate value of the shear strain is increased, and the shear strain is decreased as the principal stress which is developed in the both two sides. Since the width of the fabric is too narrow, the display is not very clear. From the strain contours of fabric width which is gradually increased (The fiber cloth width and spacing ratios were $50 \mathrm{~mm}, 60 \mathrm{~mm}$, $80 \mathrm{~mm}$, and $450 \mathrm{~mm}$ ), it can be clearly seen that the distribution of the shear strain is similar to the distribution of fiber cloth width which is $30 \mathrm{~mm}$

In the simulation experiments, when the initial load is small, some vertical cracks appear in the marginal zone of the bending tensile shear zone at first. With the increasing load, the crack extends shortly along the length of the vertical direction, and then it develops some diagonal cracks, then it generates a wide main diagonal crack throughout the beam. In Figure 5, we take the width of fiber cloth which is $60 \mathrm{~mm}$ as an example, it can be drawn that the strain of fibrous fabric is developed to the maximum in the position of the main oblique crack, and plays the most significant effect along with the gradually reducing which is along the main diagonal crack in the direction perpendicular to the sides. This explanation is consistent with the theoretical results that the damage is confirmed based on the shear failure.

By observing the strain of each load step of fibrous fabric, it can be drawn that in the early stages of loading tests, the CFRP strain is very small, and the relationship between the load and CFRP strain showed a linear growth. With the increasing load, the concrete starts to crack, and the CFRP starts to play a role gradually. The strain increase and the strain difference are increased. When the reinforced concrete beam is approaching destruction, the stress of rebar reaches to the maximum. The CFRP has played the biggest role, and the specific performance is that the CFRP strain grew faster than the previously initial strain rate of growth. In the ultimate bearing capacity destruction of the beam, the CFRP model which pastes different 
widths did not reach the limit strain 0.018 (Table 3 carbon fiber maximum strain at failure), which shows CFRP will peel when the last component is damaged.

Table 3. Maximum strain value at failure of the carbon fibers

\begin{tabular}{|c|c|c|c|c|c|}
\hline $\begin{array}{l}\text { Beam } \\
\text { number }\end{array}$ & $\begin{array}{l}\text { S-CU } \\
-0.3\end{array}$ & $\begin{array}{l}\text { S-CU } \\
-0.5\end{array}$ & $\begin{array}{l}\text { S-CU } \\
-0.6\end{array}$ & $\begin{array}{l}\text { S-CU } \\
-0.8\end{array}$ & $\begin{array}{l}\text { S-C } \\
\text { U-1 }\end{array}$ \\
\hline $\begin{array}{l}\text { The maxi- } \\
\text { mum } \\
\text { strain(10-3) }\end{array}$ & 2.03 & 2.13 & 2.24 & 1.86 & 1.61 \\
\hline
\end{tabular}

8

(a)fabric width $30 \mathrm{~mm}$
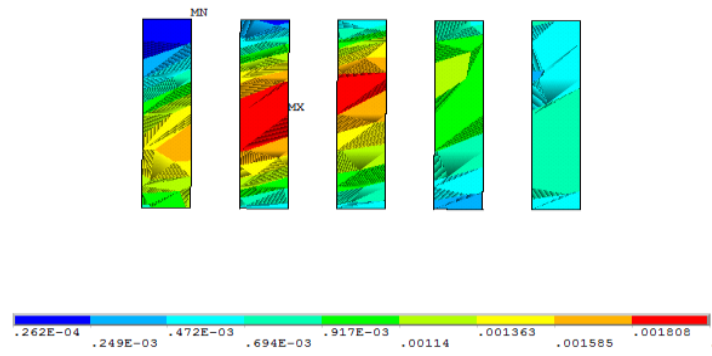

(b)fabric width $50 \mathrm{~mm}$
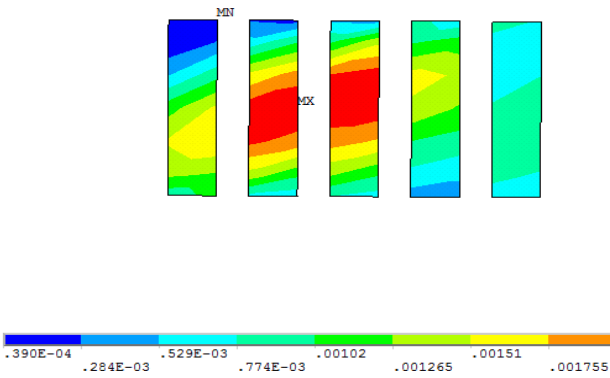

(c)fabric width $60 \mathrm{~mm}$
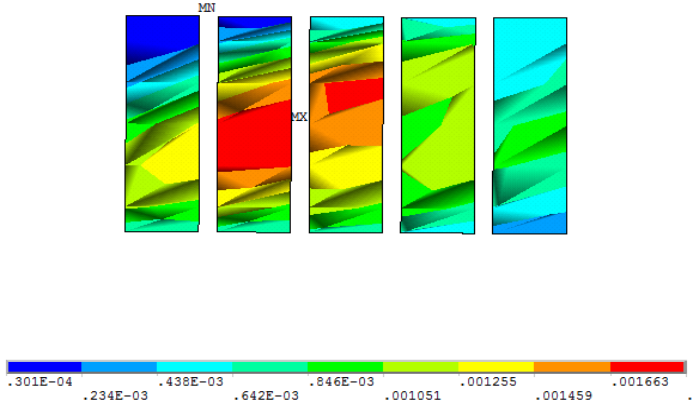

(d)fabric width $80 \mathrm{~mm}$
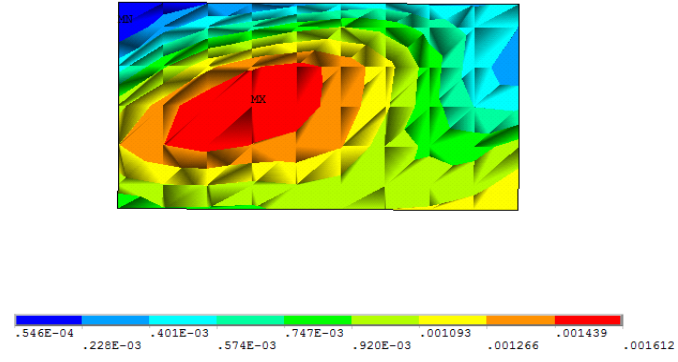

(e)fabric width $450 \mathrm{~mm}$

Figure 5. Strengthening reinforced concrete beam width of cloth of different U-shaped hoop strain contours

In addition, by comparing strain of different widths CFRP under the same load, we can found that after a concrete cracking, the greater width of CFRP, the CFRP strain under the same load increase first and then decrease, when the shop is full of carbon fiber, its strain is not the biggest, however. It can be explained that the shear capacity of beams is not increased with the increasing width of CFRP. However, when the width of CFRP reaches $60 \mathrm{~mm}$, the shear capacity has reached the most significant effect.

The main problems affecting the bearing capacity of reinforced concrete beams is the shear capacity of reinforced concrete beams, and the concrete shear failure occurs in the vertical direction of crack, but because of the relatively poor performance of concrete in tension, even if it is configured with a number of anti-shear stirrups, and the improvement of the shear capacity is limited very much. As this simulative results show that the concrete crushed site of reinforced concrete beam showed shear diagonal crack destruction. The formation of the over reinforced beam have little effect on the improvement of load bearing ability, and it is easy to cause steel waste. In response to these problems, the U-shaped outsourcing CFRP not only improves the shear performance, but also has significant economic significance.

\section{CONCLUSION}

By the analysis of pasting different widths of CFRP under concentrated load, we can draw the following conclusions:

(1) The method of pasting U-shaped hoop fiber cloth improves the ultimate bearing capacity of reinforced concrete beams, and reduces the bottom deflection value of the beam.

(2) The ultimate load is not proportional with the increase of CFRP's width, but when the width and spacing of fabric are increased by $60 \mathrm{~mm}$, the ultimate load reaches the maximum.

(3) The pasting CFRP strips can effectively improve the shear capacity of the beam than the pasting CFRP sheet. 


\section{MATEC Web of Conferences}

\section{REFERENCES}

[1] Teng Jinguang 2005. FRP Reinforced Concrete Structures, Beijing: China Building Industry Press.

[2] Ye Ping, Lu Zheng, Tengjin Guang. \& Chen Jianfei 2007. FRP reinforced concrete beams stripping capacity calculation and design structures, 37(12): 79-82.

[3] Lu Zheng, Tan strong, Ye Ping. \& Jiang whale 2004. FRP cloth - Finite element analysis of concrete interfacial bonding properties, Engineering Mechanics, 21(6): 45-50.

[4] Zhang Xiao, Ye Ping. \& Lu Zheng. 2005. U type FRP Reinforced concrete beam finite element analysis by SHEAR BEHAVIOR, Engineering Mechanics, 22 (4): 155-162.

[5] See Whale River reinforced concrete structural nonlinear finite element analysis Shaanxi: Shaanxi Science and Technology Press, 1994.120.

[6] Lu Zheng. \&Jiang whales. 2003. Use ANSYS Solid 65 element analysis of concrete structures under complex stress conditions structures, 33 (6): 22-24.

[7] had Zhenhai reinforced concrete principle Beijing: Tsinghua University Press, 1999.

[8] Lu Zheng, Feng Peng. \& Ye Ping 2003. Confined with FRP square concrete columns finite element analysis of axial compression performance, Civil Engineering Journal, 36 (2): 46-51.

[9] The design of concrete structures GB 50010-2010 Beijing: China Building Industry Press, 2010.

[10] Ye Lieping. 2002. Concrete Structures (On). Beijing: Tsinghua University Press, 309. 